\title{
Hydrogen evolution from water using CdS as photosensitizer
}

\author{
Tatiana Oncescu, M. Contineanu, and Lucia Meahcov \\ Department of Physical Chemistry, Faculty of Chemistry, University of Bucharest, \\ Bd. Republicii 13, Bucharest, RO-70346, Romania
}

\begin{abstract}
Colloidal chemical approaches are increasingly utilised for the preparation and stabilization of semiconductor nanoparticles.

We prepared a colloidal CdS in excess of $\mathrm{Na}_{2} \mathrm{~S}$ using a method described in the literature and determined the particle size from its absorption spectrum by Brus equation. A diameter of about $50 \AA$ was calculated. For the stabilization of colloid we choosed from various tested polymers a $1 \%$ in weight copolymer $(1 / 1)$, styrene/maleic anhydride. As redox catalyst we used colloidal Pt obtained "in situ" by irradiaton of $\mathrm{PtCl}_{6} \mathrm{~K}_{2}$. We established the role of each of the system partners as: CdS concentration, $\mathrm{Na}_{2} \mathrm{~S}$ excess, Pt catalyst concentration, the irradiation time, and the system temperature. We studied the influence of each participant to the hydrogen evolution in order to optimize this system.

The formation of nanosize composite particles $\mathrm{Cd}_{1-x} \mathrm{Zn}_{x} \mathrm{~S}$ showed an increasing of $\mathrm{H}_{2}$ amount generated under irradiation, in comparison with CdS particles.

The results obtained permitted us to calculate the turnover number (TO) of the system.
\end{abstract}

\section{INTRODUCTION}

The formation of hydrogen from water using irradiated semiconductor catalysts has attracted the interest of many researchers because of its possible application to solar energy conversion. Between the known catalysts, colloidal semiconductors are very interesting, because their large surface area may provide high catalytic activity. Such a colloidal semiconductor is CdS which we used in the present study.

Absorption of light by these particles creates mobil electrons $\mathrm{e}^{-}$and holes $\mathrm{h}^{+}$that migrate to the surface and undergo redox processes with the adsorbed chemical species. Pt catalyst have been loaded onto the particle surface to favorize $\mathrm{H}_{2} \mathrm{O}$ reduction with $\mathrm{H}_{2}$ generation.

Colloidal particles in solution are usually stabilized by certain reagents to prevent aggregation.

A difficulty in the preparation of colloidal semiconductor by precipitation of $\mathrm{Cd}^{+2}$ salt in excess of $\mathrm{Na}_{2} \mathrm{~S}$ consists in the fact that a certain size distribution will always be produced instead of monodisperse system.

\section{MATERIALS AND METHODS}

For the syntheses of CdS we used:

- $\mathrm{CdSO}_{4}$ (Fluka);

- $\mathrm{ZnSO}_{4}$ (Fluka);

- $\mathrm{Na}_{2} \mathrm{~S}$ (Fluka);

- $\mathrm{NaOH}$ pallets (Lachema) to assure a pH 12;

- $\mathrm{K}_{2} \mathrm{PtCl}_{6}$ prepared in our labor from $\mathrm{H}_{2} \mathrm{PtCl}_{6}$ and $\mathrm{KCl}$.

As stabilising polymers we tested:

- polyvinil alcohol, PVA (Austranal);

- $1 \%$ in weight copolymer styrene/maleic anhydride $(1 / 1)$ COP;

- polyacrylic acid, PAA (Fluka);

- sodium hexametaphosphat, HMP (Fluka).

Absorption spectra were recorded at a SP 8000 Pye
Unicam spectrophotometer using thermostatted silica cells with a path lenght $d=0.5 \mathrm{~cm}$.

As irradiation source we used a $250 \mathrm{~W}$ Hg-lamp which emitted visible light. The samples $(5 \mathrm{ml}$ ) disposed around the Hg-lamp were irradiated in glass phials of about $10 \mathrm{ml}$ at constant temperature. The $\mathrm{pH}$ of the solutions were measured at a Radiometer $\mathrm{pH}$ meter. These phials provided with two necks, one for Ar bubbling and the other one for air evacuation through syringe needles.

The evolved $\mathrm{H}_{2}$ was analysed at a Carlo-Erba gas chromatograph using Ar as carrier gas.

\section{RESULTS AND DISCUSSIONS}

We prepared a colloidal CdS in excess of $\mathrm{Na}_{2} \mathrm{~S}$ using the recipe described by Kalyanasundaram K. et al. [1] The colloidal solutions are yellow transparent and show an absorption edge at about $550 \mathrm{~nm}$.

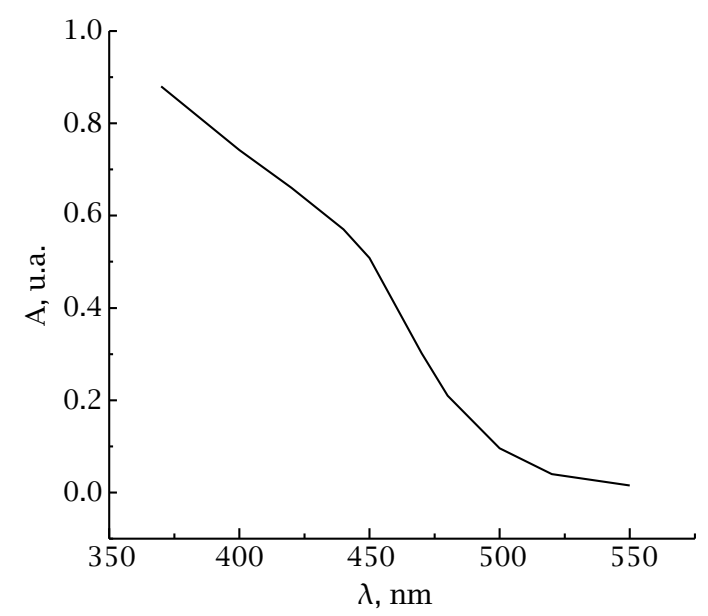

Figure 1. Absorption spectrum for CdS synthetized. 
Particle size was determined from this absorption spectrum and the experimental data fitted to [2]:

$$
\varepsilon h v=k\left(h v-E_{\mathrm{g}} \times \mathrm{e}\right)^{1 / 2}
$$

and obtained $E_{\mathrm{g}}=2.6 \mathrm{eV}$. With this value we calculated the particle size using Brus equation [3]:

$$
E_{\mathrm{g}}=E+h^{2} / 2 d_{\mathrm{p}^{2}} \mathrm{e}\left(1 / m_{\mathrm{e}}^{*}+1 / m_{\mathrm{h}}^{*}\right)-3.6 \mathrm{e} / 4 \pi D d_{\mathrm{p}},
$$

where:

$$
\begin{aligned}
m_{\mathrm{e}}^{*} & =0.19 m_{\mathrm{e}}, \\
m_{\mathrm{h}}^{*} & =0.8 m_{\mathrm{e}}\left(m_{\mathrm{e}}=9.11 \times 10^{-31} \mathrm{~kg}\right), \\
\mathrm{e} & =1.602 \times 10^{-19} \mathrm{C}, \\
D & =5.7 D_{0}, \quad D_{0}=8.854 \times 10^{-12} \mathrm{C}^{2} \mathrm{~J}^{-1} \mathrm{~m}^{-1},
\end{aligned}
$$

and obtained a value of $d_{\mathrm{p}} \approx 50 \AA$ A ranging in the domain of $Q$ particles.

Irradiation of CdS colloidal solutions lead to charge separation that migrate to the particles surface and participate at the reduction and oxidation processes on the colloid-electrolyte interface. Since the lifetime of the photogenerated carriers is very short, only very fast reactions with adsorbed scavengers on the particle surface lead to the formation of reduced or oxidised species in solution.

It is known, that on irradiation with visible light characterised by energies higher than $E_{\mathrm{g}}$, the following processes shown in Figure 2, take place:

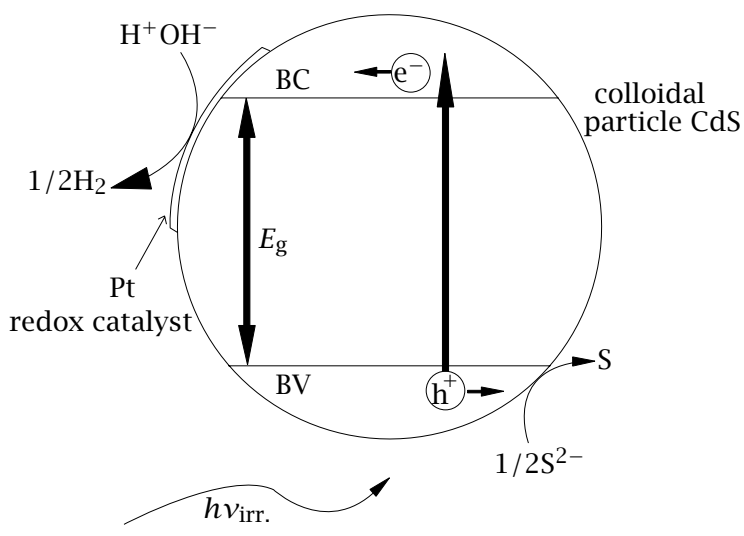

Figure 2. Processes on an irradiated colloidal CdS particle $\left(h v_{\text {irr. }} \geq E_{\mathrm{g}}\right)$.

charge separation (light induced formation of electrons and holes)

$$
\mathrm{CdS}+h v \rightarrow \mathrm{CdS}\left(\mathrm{e}_{\mathrm{BC}}^{-}+\mathrm{h}_{\mathrm{BV}}^{+}\right),
$$

recombination (back radiative process)

$$
\mathrm{e}_{\mathrm{BC}}^{-}+\mathrm{h}_{\mathrm{BV}}^{+} \longrightarrow h v,
$$

back nonradiative process

$$
e_{\mathrm{BC}}^{-}+\mathrm{h}_{\mathrm{BV}}^{+} \longrightarrow \text { heat, }
$$

hydrogen evolution

$$
2 \mathrm{e}_{\mathrm{BC}}^{-}+2 \mathrm{H}_{2} \mathrm{O} \rightarrow \mathrm{H}_{2} \uparrow+2 \mathrm{HO}^{-},
$$

holes scavenge (excess of $\mathrm{Na}_{2} \mathrm{~S}$ )

$$
2 \mathrm{~h}_{\mathrm{BV}}^{+}+\mathrm{S}^{-2} \rightarrow \mathrm{S}
$$

polysulphide formation

$$
n \mathrm{~S}+\mathrm{S}^{-2} \rightarrow \mathrm{S}_{\mathrm{n}}^{-2}
$$

oxygen-free photocorrosion of CdS

$$
2 \mathrm{~h}^{+}+\mathrm{CdS} \rightarrow \mathrm{Cd}^{+2}+\mathrm{S} .
$$

An other process is the desorption of the products (S) from the colloid surface, when the desorbed species may still remain on the vicinity of the colloidal particles because of the possible interactions with the polymer stabilizer as (6) shows.

CdS has a conduction band of about $-0.8 \mathrm{~V}$ ( $v s$. NHE) and provides enough energy to reduce water. By using a Pt catalyst adsorbed onto the particle surface the reaction rate of the water reduction (4) is substancial increased. Hydrogen evolution is accompanied by the oxidation of the sacrificial electron donor $\mathrm{S}^{-2}$, as process (5) shows.

Colloidal particles in solution are usually stabilized by certain reagents to prevent aggregation. The rates and yields of reactions in these microheterogeneous systems can be dramatically changed according to the nature of the microenvironment. Therefore, we tested various stabilizers and observed that the copolymer styrene/maleic anhydride COP, is the best one as Table 1 shows.

Table $1 . \mathrm{H}_{2}$ evolution in the presence of various stabilizer.

\begin{tabular}{lc}
\hline Stabilizer & {$\left[\mathrm{H}_{2}\right](\mu \mathrm{mol})$} \\
\hline polyvinil alcohol $(0.03 \%)$ & 51 \\
copolymer styrene/maleic & 79 \\
anhydride $(0.006 \%)$ & \\
polyacrylic acid $(0.2 \%)$ & 45 \\
sodium hexametaphosphat $(0.6 \%)$ & 49 \\
\hline
\end{tabular}

As catalyst we used colloidal platinum in various concentrations. It was prepared "in situ" from an aqueous solution of $\mathrm{K}_{2} \mathrm{PtCl}_{6}$ on its irradiation. The next table presents our results under the following conditions:

$$
\begin{aligned}
& {[\mathrm{CdS}]=8.73 \times 10^{-4} \mathrm{M} ;} \\
& {\left[\mathrm{Na}_{2} \mathrm{~S}\right]_{\text {excess }}=1 \times 10^{-2} \mathrm{M} ;} \\
& {[\mathrm{COP}]=0.006 \% ; \mathrm{pH} 12 ; \mathrm{T}=23^{\circ} \mathrm{C} ;} \\
& t_{\text {irr. }}=6 \mathrm{~h} \text { and } v_{\text {irr. }}=5 \mathrm{ml} .
\end{aligned}
$$


Table 2. Variation of hydrogen evolution with the catalyst concentration.

\begin{tabular}{cc}
\hline$[\mathrm{Pt}] \times 10^{-5} \mathrm{M}$ & {$\left[\mathrm{H}_{2}\right](\mu \mathrm{mol})$} \\
\hline 0.5 & 97 \\
1 & 156 \\
2.5 & 153 \\
5 & 162 \\
6.5 & 170 \\
8 & 164 \\
10 & 110 \\
50 & 9 \\
\hline
\end{tabular}

This table shows that a catalyst concentration of $6.5 \times 10^{-5} \mathrm{M}$ is suitable for our experiments.

We varied also the colloidal CdS concentration (1$9 \times 10^{-4} \mathrm{M}$ ) keeping constant the other components. We established that the most advantageous concentration of CdS is $8.73 \times 10^{-4} \mathrm{M}$. This concentration was kept always constant in our experiments.

We checked the influence of $\mathrm{COP}$ concentration on $\mathrm{H}_{2}$ evolution. The results are shown in Table 3.

Table 3. The amount of hydrogen generated for different copolymer concentrations.

\begin{tabular}{cc}
\hline$[\mathrm{COP}] \%$ & {$\left[\mathrm{H}_{2}\right](\mu \mathrm{mol})$} \\
\hline 0.0006 & 12.1 \\
0.003 & 19.7 \\
0.006 & 126 \\
0.03 & 108 \\
0.1853 & 115 \\
\hline
\end{tabular}

We opted for $[\mathrm{COP}]=0.006 \%$.

An other important factor is the excess of $\mathrm{Na}_{2} \mathrm{~S}$. The higher sulphide concentration, the higher $\mathrm{H}_{2}$ generation. After a critical value of $\mathrm{Na}_{2} \mathrm{~S}$ excess $\left(1 \times 10^{-2} \mathrm{M}\right)$ as Figure 3 shows, $\mathrm{H}_{2}$ evolution is less favorized because of the competition between Pt particles and sulphide ions to occupy the colloidal CdS surface.

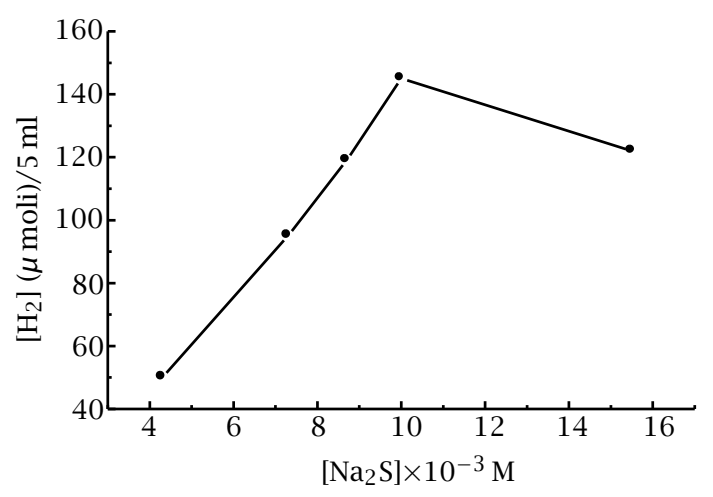

Figure 3. Variation of hydrogen amount with $\left[\mathrm{Na}_{2} \mathrm{~S}\right]$ excess.
As literature shows the temperature contributes also to obtain higher amounts of $\mathrm{H}_{2}$. Our experimental results confirm also this observation. Under the experimental conditions: $[\mathrm{CdS}]=8.73 \times 10^{-4} \mathrm{M}$; $\left[\mathrm{Na}_{2} \mathrm{~S}\right]_{\text {excess }}=1 \times 10^{-2} \mathrm{M}$; $[\mathrm{Pt}]=6.5 \times 10^{-5} \mathrm{M}$; $[\mathrm{COP}]=$ $0.006 \%$; pH 12; $T=23,38$ and $58{ }^{\circ} \mathrm{C}$ we obtained the behaviour pointed out in Figure 4.

In these experiments at each constant temperature was varied the irradiation time, what permitted us to calculate a zero order rate constant for $\mathrm{H}_{2}$ as follows:

$$
\begin{aligned}
& k_{0}{ }^{23}=2.24 \times 10^{-6} \mathrm{Ms}^{-1} ; \\
& k_{0}{ }^{38}=3.34 \times 10^{-6} \mathrm{Ms}^{-1} ; \\
& k_{0}{ }^{58}=6.53 \times 10^{-6} \mathrm{Ms}^{-1} .
\end{aligned}
$$

These values lead to a low activation energy, typical for a physical process, in this case probably the adsorption-desorption process:

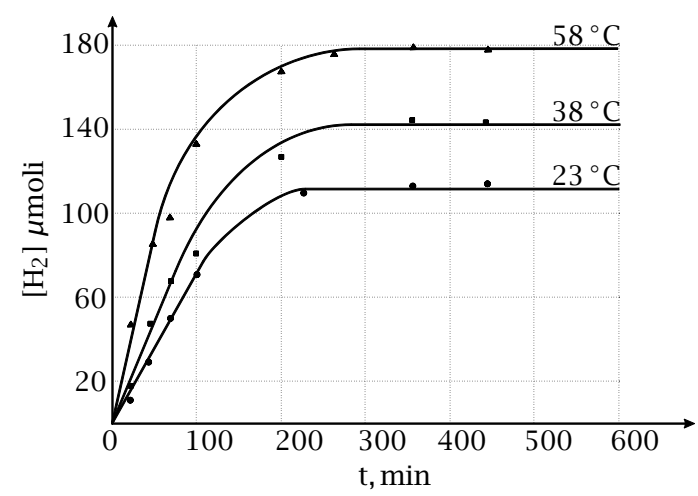

Figure 4. Influence of irradiation time for different work temperatures.

\section{$E_{\mathrm{a}}=10.21 \mathrm{~kJ} / \mathrm{mol}=2.45 \mathrm{kcal} / \mathrm{mol}$}

This figure shows also that is not necessary to prolonged the irradiation time after 4 hours in order to obtain more $\mathrm{H}_{2}$. This behaviour may be due to the competition between process (4) and (5). One can appreciate that the first 90 minutes $v_{\mathrm{H}_{2}}>v_{\mathrm{S}}$. After this period $v_{\mathrm{H}_{2}}$ decrease gradually concomitant with $v_{\mathrm{S}}$ increasing and after 240 minutes these two rates equalize and the generated $\mathrm{H}_{2}$ keeps constant.

We mentioned that during this irradiation time at $23^{\circ}$ and $38^{\circ} \mathrm{C}$ too, an abundant colloidal sulphur is observed.

The higher temperature, the amount of the evolved $\mathrm{H}_{2}$ at each time increases. At the same time the amount of colloidal sulphur diminishes by the formation of the soluble polysulphide as process (6) shows. So, at the highest temperature, $58^{\circ} \mathrm{C}$, the solution becomes clear and red-brown leading to the highest amount of $\mathrm{H}_{2}$.

Finally, we calculated the turnover number (TO) of cadmium sulphide for the generation of hydrogen in an optimized system during 4 hours irradiation:

$\mathrm{TO}_{\mathrm{CdS}}=\left[\mathrm{H}_{2}\right] / 2[\mathrm{CdS}]$

We found $\mathrm{TO}_{\mathrm{CdS}}=22$ for the temperature equal to $58^{\circ} \mathrm{C}$ and $\mathrm{TO}_{\mathrm{CdS}}=15$ for $38^{\circ} \mathrm{C}$. 
By adding concomitant $\mathrm{ZnSO}_{4}$ and $\mathrm{CdSO}_{4}$ in the $\mathrm{Na}_{2} \mathrm{~S}$ solution, it formes a composite with the formula $\mathrm{Cd}_{0.53} \mathrm{Zn}_{0.47} \mathrm{~S}$. The additions of $\mathrm{Zn}^{+2}$ assures a more negative potential for the composite than that of pure $\mathrm{CdS}$, what favorizes the reduction of water. At the same time one notices that the increasing of $\mathrm{ZnS}$ quantity over a critical value has a negative influence on $\mathrm{H}_{2}$ evolution as Figure 5 shows.

At higher $\mathrm{Zn}^{+2}$ concentration, multilayers of $\mathrm{ZnS}$ will deposit on the particle surface which has a larger bandgap than CdS [4]. Under these conditions the absorption spectrum shifts toward the shorter wave lengths what diminishes the efficiency of the incident visible light.

For the most favourable composite with the formula $\mathrm{Cd}_{0.53} \mathrm{Zn}_{0.47} \mathrm{~S}$ a turnover number higher than in the zinc absence was calculated. So for the temperatures $58^{\circ}$ and $38{ }^{\circ} \mathrm{C}, \mathrm{TO}_{\text {comp. }}=58$ and 36 respectively.

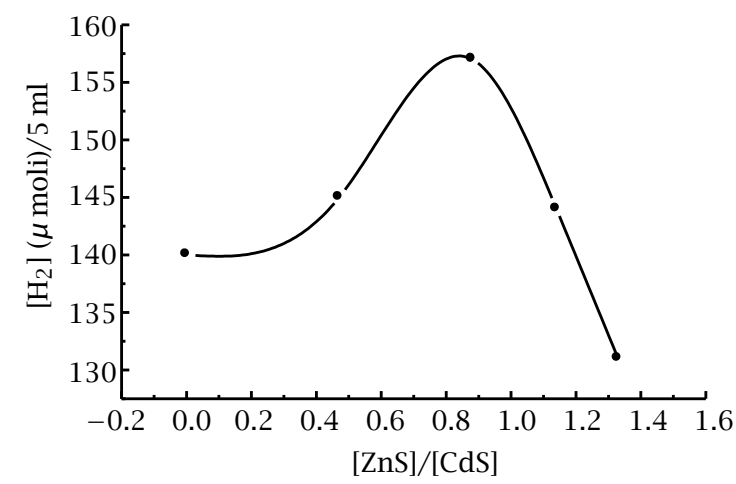

Figure 5. Effect of $[\mathrm{CdS}] /[\mathrm{ZnS}]$ coprecipitation on hydrogen evolution

\section{CONCLUSIONS}

We prepared a colloidal CdS in excess of $\mathrm{Na}_{2} \mathrm{~S}$ which shows an absorption edge of about $550 \mathrm{~nm}$. Size particle of $50 \AA$ was determinated from the absorption spectrum.

Irradiation of CdS colloidal solutions lead to the formation of electrons and holes that can migrate to the particle surface and participate at reduction and oxidation processes on the colloid-electrolyte interface.
We tested the importance of each participant concentration for the hydrogen generation. Preparation of stable colloidal semiconductor system allowed the investigation of the kinetics of $\mathrm{H}_{2}$ formation under irradiation at various temperatures.

The values of rate constants calculated for each work temperatures lead to a low activation energy, typical for a physical process, in this case the adsorptiondesorption process:

$E_{\mathrm{a}}=10.21 \mathrm{~kJ} / \mathrm{mol}=2.45 \mathrm{kcal} / \mathrm{mol}$

At the lower investigated temperatures an abundant colloidal sulphur is observed, whereas at $58^{\circ} \mathrm{C}$ the solution is clear and becomes red-brown by the dissolution of sulphur in $\mathrm{Na}_{2} \mathrm{~S}$ with polysulphide formation.

We prepare also a composite by CdS and ZnS coprecipitation. The addition of zinc assures a more negative potential of the composite than that of pure CdS, what favorized the reduction of water. At the same time one notices that the increasing of zinc quantity over a critical value, has a negative influence on $\mathrm{H}_{2}$ evolution. Probably, such a composite shifts the absorption spectrum toward the shorter wavelengths what diminished the efficiency of the incident light with preponderant visible radiations.

Finally, we calculated the turnover number (TO) of cadmium sulphide in an optimized system during 4 hours irradiation, for the generation of hydrogen from CdS colloidal solution and found $\mathrm{TO}_{\mathrm{CdS}}=22$ at $58^{\circ} \mathrm{C}$ and $\mathrm{TO}_{\mathrm{CdS}}=15$ for $38^{\circ} \mathrm{C}$. The composite leads to a higher $\mathrm{TO}$ as follows: $\mathrm{TO}_{\mathrm{c}} \mathrm{Omp} .=58$ at $58^{\circ} \mathrm{C}$ and 36 at $38^{\circ} \mathrm{C}$.

The modest values of the turnover numbers suggests that the efficiency of $\mathrm{H}_{2}$ generation may be increased by preparing a colloidal CdS of higher particle size than $100 \AA$ to exceed the domain of $Q$ particles.

\section{REFERENCES}

[1] K. Kalyanasundaram, E. Borgarello, D. Dounghoung, and M. Gratzel, Angew. Chem. 93 (1981), 1012.

[2] Y. Wang, A. Suna, W. Mahler, and R. Kasowski, J. Chem. Phys. 87 (1987), 7315.

[3] L. E. Brus, J. Chem. Phys. 80 (1984), 4403.

[4] B. A. Parkinson, A. Heller, and B. Miller, J. Electrochem. Soc. 126 (1979), 954. 


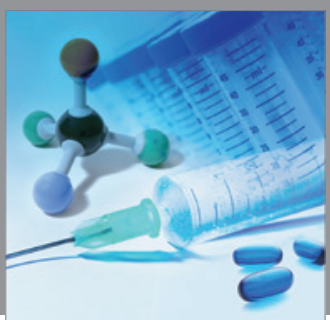

International Journal of

Medicinal Chemistry

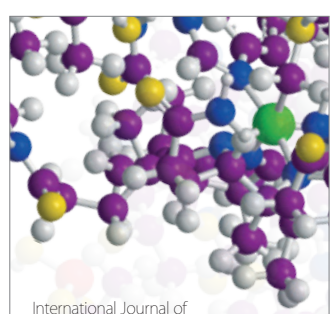

Carbohydrate Chemistry

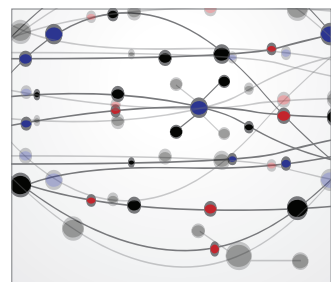

The Scientific World Journal
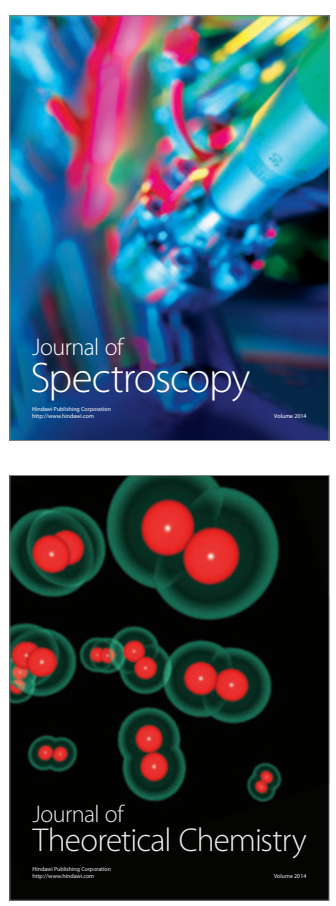
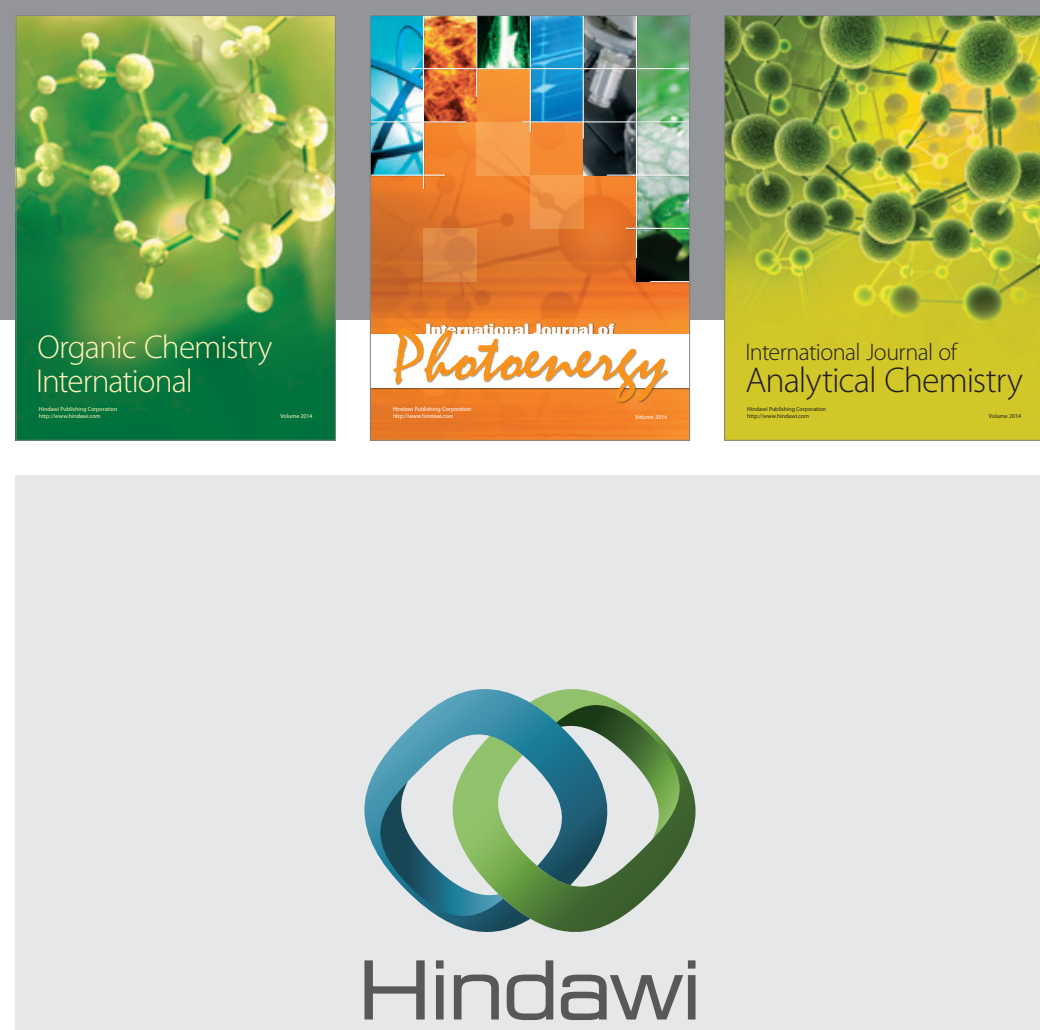

Submit your manuscripts at

http://www.hindawi.com
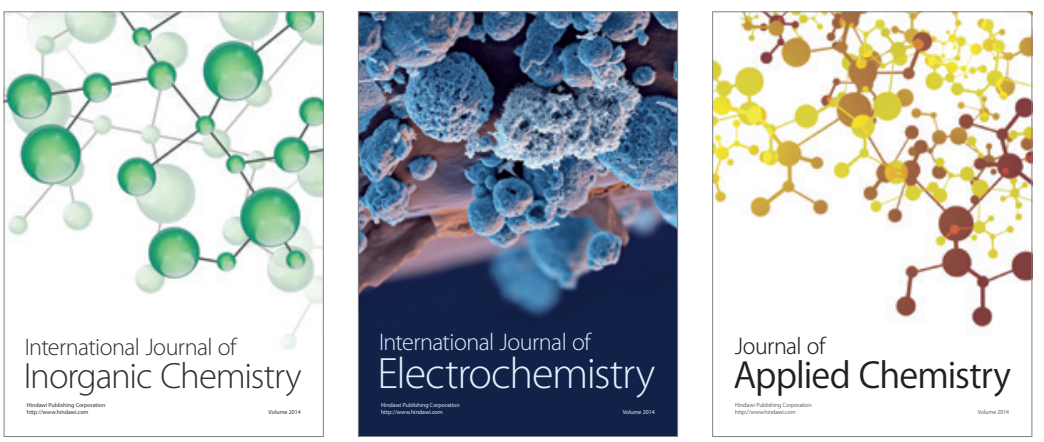

Journal of

Applied Chemistry
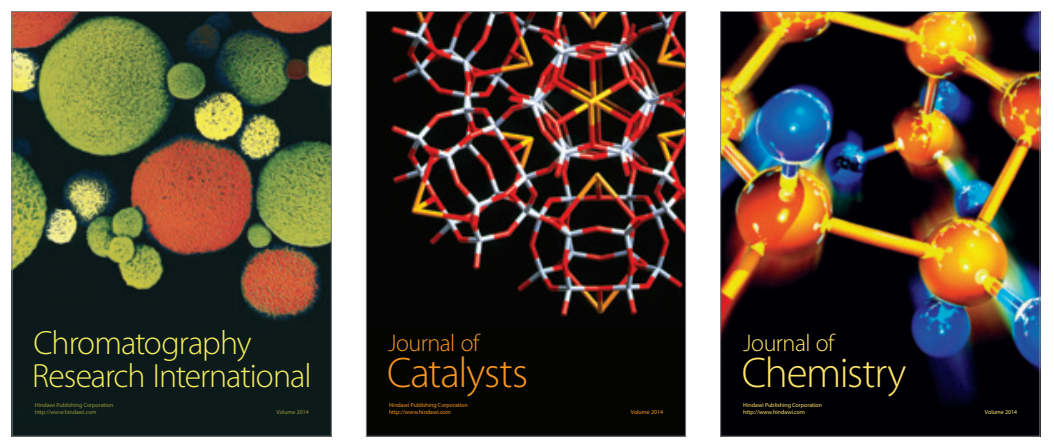
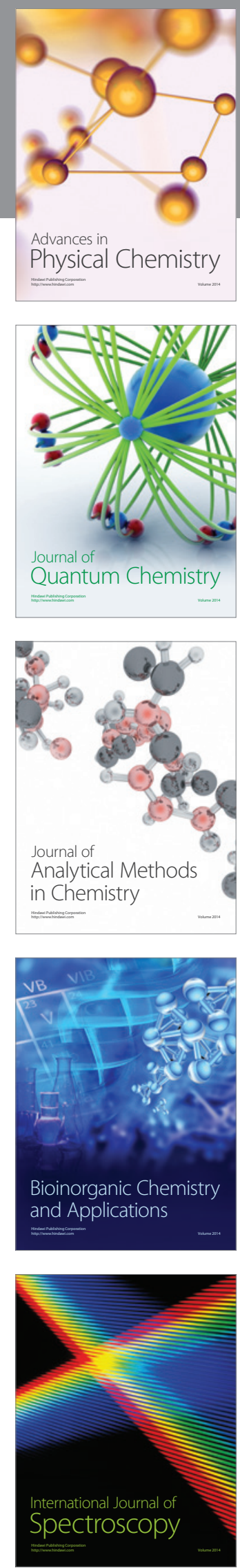